\title{
THE EFFECT OF AQUATIC AND TERRESTRIAL ENVIRONMENTAL FACTORS ON THE INTERACTION BETWEEN GRAND TETON BOREAL TOADS AND A LETHAL FUNGAL PATHOGEN
}

\section{Peter J. Murphy, Sophie St-Hilaire \& Charles Peterson $\downarrow$ IDAho State University POCATELLO}

\section{$\downarrow \quad$ INTRODUCTION}

Batrachochytrium dendrobatidis $(B d)$, the chytrid fungus which infects keratinized amphibian skin and causes the lethal disease chytridiomycosis, has been linked to population declines and extinctions worldwide (Lips et al. 2006). Amphibians infected with $B d$ may suffer a variety of outcomes. Individuals of some species have been killed by $\leq 100 B d$ zoospores, while other species, such as the North American bullfrog Rana catesbiana, are highly resistant (Daszak et al. 2004). Within an amphibian species, populations may also respond differently to $B d$, with some declining et al. remaining stable (Kriger and Hero 2006). Divergent outcomes among species and populations with respect to $B d$ may arise from at least three factors, or their interaction:

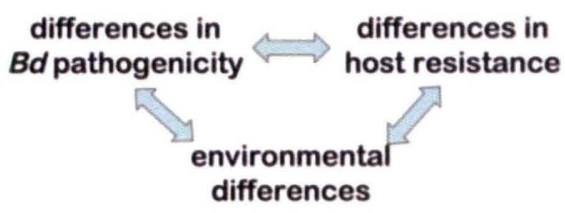

In the past several years, we have been investigating the role of each of these factors in the epidemiology of $B d$ in boreal toads, Bufo boreas boreas. $B d$ has been linked to recent, severe declines in Colorado boreal toads (Muths et al. 2003). But similar declines have not been documented in these toads from northwestern Wyoming, within and surrounding Grand Teton National Park (Corn 2007). This is true even though Grand Teton boreal toads i) carry $B d$ at high levels across Grand Teton breeding populations (Figure
$1 \mathrm{~A}$ and $\mathrm{B}$ and Figure 2) will die when exposed to $B d$ under laboratory conditions (Fig. 1C; Murphy et al. 2008). These findings suggest that in the field, environmental factors may influence the interaction between the host and pathogen, allowing boreal toads to reduce the virulence of $B d$.

A recent model for the epidemiology of chytridiomycosis based on Rana muscosa, the yellowlegged frog, in the Sierra Nevada amphibian (Briggs et al. 2005) demonstrates that the persistence of $B$. dendrobatidis in a susceptible population requires either, or both, of the following conditions: i) the pathogen, $B$. dendrobatidis, must persist outside of the host, or ii) at least some post-metamorphic individuals must survive infection. With regard to (ii), a 7-week telemetry study in 2004 within Grand Teton National Park (SC, Fig. 1A) found that 4 toads $B d$ positive in July were negative by late August, direct evidence that these toads can survive infection (Spear et al. 2005). At this stage, our current knowledge about the interaction between $B d$ and boreal toads in the Grand Teton ecosystem (GRTE) suggests two non-exclusive hypotheses:

1. Independent survival of $B$. dendrobatidis:

$B d$ persists in GRTE water sources independent of boreal toads, and reinfects them periodically.

2. Habitat selection favors host resistance: Environmental conditions and behavior allow boreal toads to survive $B d$ infection in the field. 
Does $B d$ persist long-term in the aquatic environment (hypothesis 1), independent of the keratin in amphibian skin thought to be required for its growth and reproduction? No non-amphibian hosts have yet been found, but closely related chytridiomycetes are saprophytic, and Johnson and Speare (2003) have shown $B d$ persistence without an alternative host for 50 days in water. $B d$ will also grow and reproduce on keratin-free, tryptone-based media in the lab.

Prior work also suggests that environmental factors and amphibian behavior may influence amphibian susceptibility to chytridiomycosis (hypothesis 2). Seasonal changes in temperature appear to play a role in disease outbreaks: the incidence of chytridiomycosis was higher in cooler seasons in Australia (Berger et al. 2004). Experimentally, amphibians exposed to warmer temperatures had lower rates of infection (Panama; Murphy and Lips, unpublished manuscript) and were able to clear infections at temperatures above $35^{\circ} \mathrm{C}$ (Australia; Woodhams et al. 2003). Hence, amphibians, by increasing their body temperature through basking, may clear $B d$ from their skin. The desire to dry out and bask was suggested by infected toads in our 2006 experiment which selected dry locations in aquaria much more often than controls (Fig. 1D).

In work funded in part by the University of Wyoming National Park Service Research Center, we assessed evidence for both hypothesis 1 and 2 from May to November 2007. We summarize our findings here, although genetic analyses of amphibian tissues collected during the summer of 2007 are still outstanding.
A

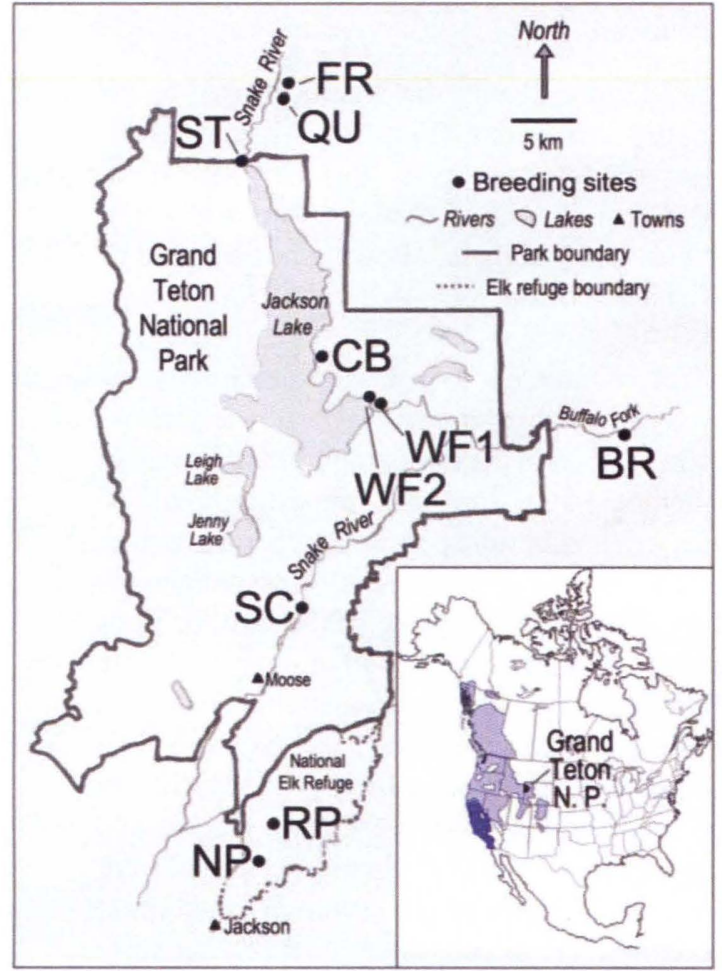

B
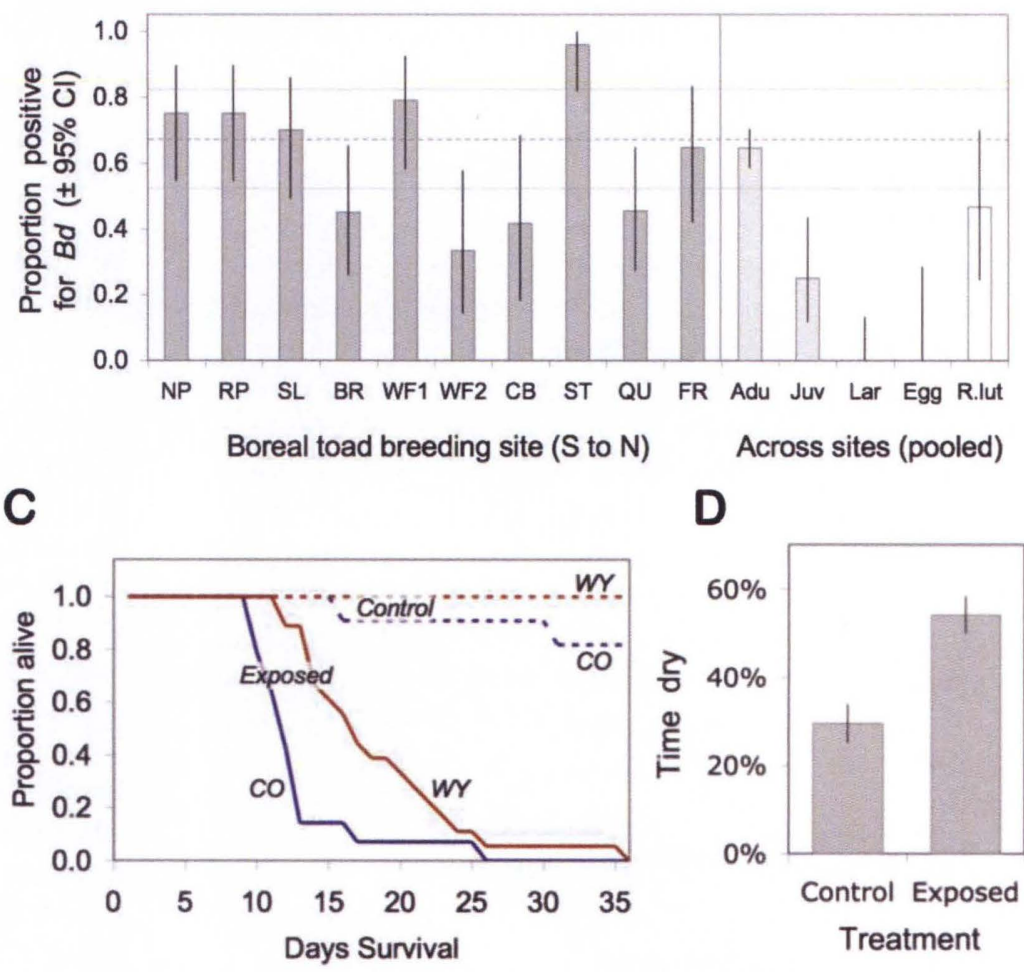

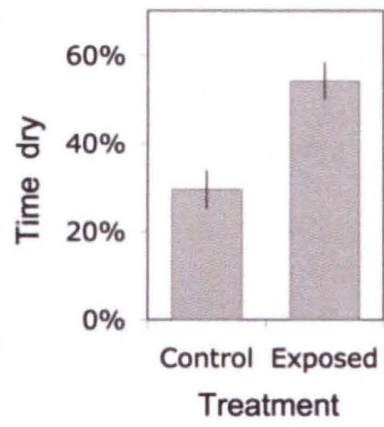

Figure 1. The chytrid pathogen $B d$ is widespread in northwestern Wyoming boreal toads, Bufo boreas boreas, and lethal to them in the laboratory. A. Ten boreal toad breeding sites in the Grand Teton ecosystem where the prevalence of $B d$ was assessed in 2006. From S to N the sites were: Nowlin Pond (NP), Romney Pond (RP), Schwabacher's Landing (SC), Blackrock Pond (BR), Willow Flats 1 and 2 (WF1,2), Colter Bay (CB), Steamboat Mountain (ST), Snake River Quarry (QU), and Flagg Ranch (FR). Inset shows the range of the western toad, B. boreas, subspecies: light shading, boreal toad; dark shading: California toad, $B$. $b$. halophilus. B. Prevalence ( $\pm 95 \%$ binomial CI) of $B d$ in boreal toad adults at 10 sites (dark bars, $n \geq 12$ per site), and pooled across sites by lifestage (light bars) and in co-occurring spotted frogs, $R$. luteiventris (white bars). Prevalence was estimated with a PCR-based assay from non-lethal skin swabs (adults, ADU, and juveniles, JUV) or tissue samples (larvae, LAR, and EGGs). The dashed line gives the grand mean prevalence in adult toads (67\%, weighted by the number tested per site), with surrounding $95 \% \mathrm{CI}(d f=9$, light lines). C. Survivorship of juvenile boreal toads, raised from tadpoles, in a 36-day laboratory study based on exposure to $B d$ (4 day dose $\approx 4.5 \times 10^{6}$ zoospores/toadlet vs. non-exposed controls) and source population (Colorado, Native Aquatic Species Restoration Facility, vs. Wyoming, BR). In a proportional hazards analysis, exposure to $B d$ reduced survival $(P<0.001)$, with Wyoming toadlets living slightly longer than Colorado toadlets $(P=0.052)$. D. $B d$-exposed toadlets selected dry microsites in aquaria nearly twice as often as controls $(P<0.001)$ 


\section{METHODS}

\section{Independent survival of Bd}

To evaluate the possibility of the independent survival of $B$. dendrobatidis, we sampled the water for $B d$ at sites used by boreal toads both i) during amphibian occupancy and ii) after amphibian activity had ceased for the season. We sampled water at four boreal toad sites, NP, SC, BR, and QU (Figure 1A), which encompass a latitudinal gradient within GRTE. Two of these, NP and $\mathrm{BR}$, are apex monitoring sites of the USGS Amphibian Research Monitoring Initiative (ARMI). Previous work on boreal toads and spotted frogs, funded through the UW-NPS (to St-Hilaire, 2005, and Spear 2004) was conducted at these sites. Hence, our findings increase the temporal record of host-pathogen interactions between $B d$ and amphibians at these sites.

To test for $B d$ in water, we used a filtering and PCR-based assay recently developed by Kirshstein et al. (2007). The protocol can detect $B d$ at concentrations of $\sim 0.1$ zoospore per liter. We sampled water at four times:

1) breeding (mid-May)

2) tadpole development (early July)

3) metamorphosis (mid-August)

4) post-toad activity (mid-November).

At each site, we collected water at two locations around the breeding pond where amphibians (adults, tadpoles, or metamorphs) were, or had been, observed. A sample was collected by pumping as much water as possible through a STERIVEX filter $(0.2 \mu \mathrm{m}$ pore size $)$, with a target volume of 1 liter, although filters often clogged after $\sim 500 \mathrm{ml}$. At each location, we collected 2-3 replicate samples, with the number limited by processing costs (\$67 per filter). At Schwabacher's Landing (SC), we also filtered water at sites where no breeding was observed but that were frequented by boreal toads based on telemetry in 2004 (Spear et al. 2005). These nonbreeding samples were taken in July, August, and November at three sites, with 2 replicates per site. Filters were frozen and tested for $B d$ using quantitative PCR by Julie Kirshtein (Voytek Lab, USGS, Reston, VA). Over the season, a total of 90 samples were collected, plus 10 distilled water 'blanks' to control for possible PCR contaminants.

\section{Environmental effects on the susceptibility of boreal toads to chytridiomycosis}

In 2007, we evaluated the potential effect of the environment on boreal toad susceptibility to $B d$ indirectly in two ways. First, we tested $B d$ prevalence in boreal toad adults, larvae, and juveniles as average temperatures increased in GRTE from May through August. Second, we used physical models of boreal toads to estimate their operative environment, in particular with reference to clearing $B d$, the temperature maxima attained and evaporative costs experienced while basking over the season.

1. Seasonal changes in Bd prevalence-At $\mathrm{NP}, \mathrm{SC}, \mathrm{BR}$, and QU, concurrent with water sampling, we collected skin swabs or tissue samples in $95 \%$ ethanol to test for $B d$ prevalence using qPCR (Boyle et al. 2004). In May, we collected 10-second skin swabs from 20 breeding adults per site. In July, 20 individual tadpoles were euthanized per site from schools of over 10,000. In August, we collected 10-second skin swabs for 20 metamorphs per site using the same methodology as in May.

2. The operative environment of boreal toads - We used recently developed physical models of boreal toads (Bartelt and Peterson 2005) to quantify the temperature and evaporative water-loss profiles experienced by toads at habitat extremes over the activity season. We set out 4 model arrays at SC, two near the main breeding pond, and two $>500 \mathrm{~m}$ distant (selected based on 2004 telemetry). Each consisted of 4 adult-toad sized, copper pipe models $(60 \mathrm{~mm}$ long x $25 \mathrm{~mm}$ diameter, semi-flattened), set out in two wet-dry pairs. One wet-dry pair was placed in an open area $(\leq 25 \%$ canopy cover), and one in a closed area ( $\geq 75 \%$ canopy cover). Models were covered with brown cotton cloth that closely matched toad skin color and reflectance and connected via a thermister to a data logger that recorded temperature every 15 minutes. Wet models were kept moist, mimicking the evaporative cooling effect of toad skin, by submerging one long end of their cloth cover in a buried 41 water source (filled weekly). Within a pair, wet and dry models were placed 3-5 cm apart. At each closed-canopy site, an additional shaded sensor $40 \mathrm{~cm}$ above ground recorded air temperature and relative humidity every 15 minutes. Additional loggers recorded water temperature at $10 \mathrm{~cm}$ depth near each array: i.e., in the breeding pond ( 2 arrays) or in a shallow, persistent stream (2 arrays). Arrays were set up on 15-June and retrieved on 17-November.

For each array, we calculated hourly means for twelve 10-day periods from mid-June to mid-October. Means were determined for wet and dry model temperatures, and evaporative water loss for closed and open sites at each array. In addition, we calculated hourly means by period for each array for air temperature, relative humidity, and water temperature. The difference between dry and wet model temperature was used to 
estimate evaporative water loss, based on a relationship determined for models under a range of temperatures and humidities: water loss $(\mathrm{ml} / \mathrm{min})=0.0048+$ $0.0063 *\left(\operatorname{dry}^{\circ} \mathrm{C}-\operatorname{wet}^{\circ} \mathrm{C}\right)$.

Based on temperature thresholds from our $B d$ infection experiments and the literature, we estimated the average number of hours per day habitat was available at $\mathrm{SC}$ in which toads could raise their temperatures to $19^{\circ} \mathrm{C}$, $25^{\circ} \mathrm{C}, 28^{\circ} \mathrm{C}$, and $37^{\circ} \mathrm{C}$. The former two thresholds are from an ongoing experiment at ISU: 4 boreal toads exposed to $10^{5} \mathrm{Bd}$ zoospores whose average 24 hour and average maximum temperatures were 19 and $25^{\circ} \mathrm{C}$ carried high levels of $B d$ in their skin but did not die of chytridiomycosis in over 160 days (as of 11 November 2008). Conversely, toads exposed to a similar $B d$ dose under similar conditions, but kept at $15^{\circ} \mathrm{C}$ (avg max $\left.16^{\circ} \mathrm{C}\right)$ all died in $\leq 45$ days $(n=12)$. At $28^{\circ} \mathrm{C} \mathrm{Bd}$ growth ceased in pure culture (Piotrowski et al. 2004), and $B d$ was cleared from skin in amphibians held at $37^{\circ} \mathrm{C}$ for 16 hours (Woodhams et al. 2003).

\section{$\uparrow \quad$ ReSUlts}

\section{Independent survival of Bd}

We detected $B d$ in water during all 4 sampling periods, but it was most widely present during breeding season (Fig. 2). During breeding, 6 of 18 filters were $B d$ positive, while post-breeding, only 8 of 72 were positive. Likewise, $B d$ was detected in water at 3 of 4 sites during breeding (May), 2 of 4 sites when tadpoles and metamorphs were present (July and August), and 1 of 4 sites post-activity (November). In positive samples, $B d$ zoospore concentrations estimated by qPCR ranged from 4/liter (August) to 64/liter (May).

\section{Environmental effects on the susceptibility of boreal toads to chytridiomycosiS}

1. Seasonal changes in Bd prevalence. We collected skin swabs from breeding boreal toads (May) and metamorphs (August) and tissue samples from tadpoles (July) to test for $\mathrm{Bd}$ prevalence over time at 4 sites (NP, SC, BR, QU). These $\sim 200$ samples await qPCR analysis.

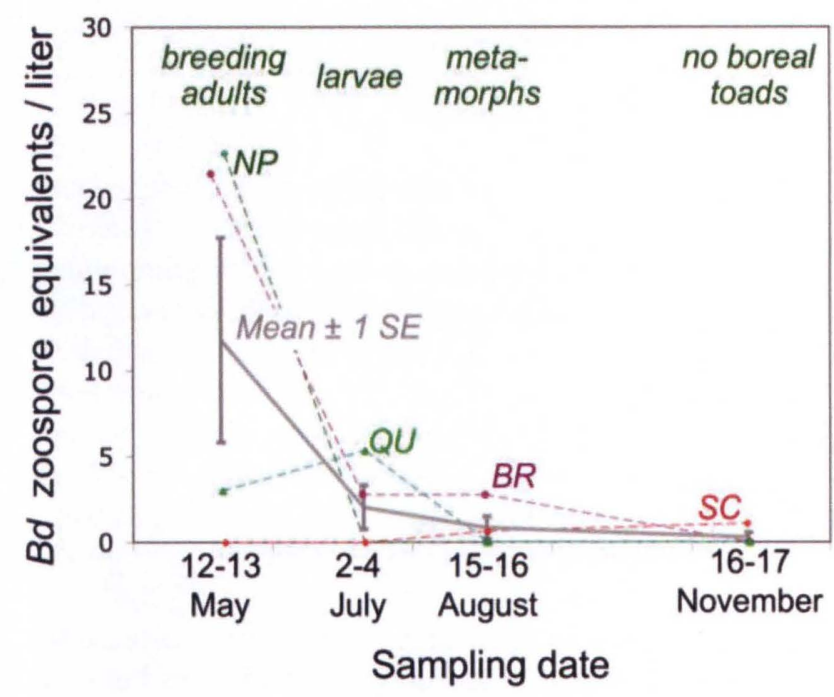

Figure 2. Prevalence of $B d$ in the water of boreal toad breeding sites (NP, SC, BR, QU, dashed lines; mean, solid gray line) from the beginning of the activity season through post-activity, as measured by filtration ( $n=90,0.2-0.91$ filtered) and a specific qPCR assay.

\section{Estimating the operative environment of boreal} toads-The trends in average temperature and evaporative water loss obtained from physical models are shown as an environmental envelope defining the extremes available to boreal toads in open- vs closedcanopy habitat from mid-June to mid-October 2007 (Figure 3). The temperature envelope was largest in midsummer (Jul 1-10), and shrunk to its smallest size in midfall (Oct 11-20), when most boreal toads have entered hibernation. The maximums measured for wet models and estimated for evaporative water loss were in early July: $37.5^{\circ} \mathrm{C}$ and $0.15 \mathrm{ml} /$ minute.

In late June and early July, temperatures $\geq 19^{\circ} \mathrm{C}$ were available to boreal toads in open-canopy habitats for $\sim 12$ hours per day (Figure 4). Temperatures $\geq 28^{\circ} \mathrm{C}$ were available in open habitats for $\geq 6$ hours each day from mid-June through August. Temperatures $\geq 37^{\circ} \mathrm{C}$ (as measured by wet models in open habitats) were rare: an estimated single hour in early July. 


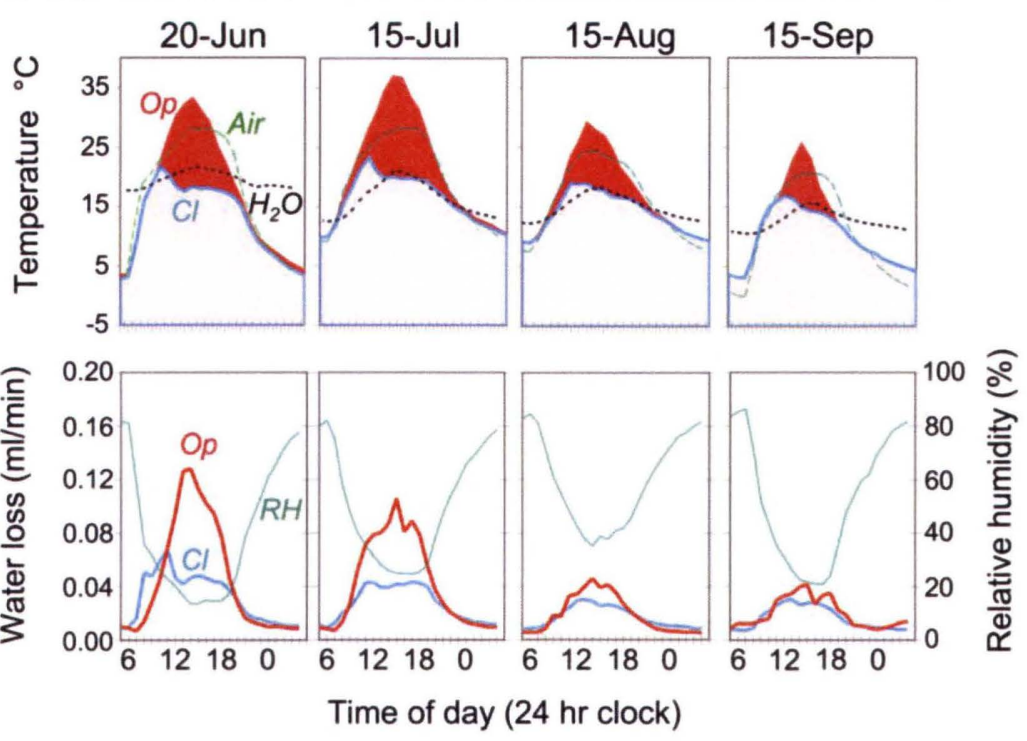

Figure 3. Extremes of temperature and evaporation in open $(\mathrm{Op})$ and closed $(\mathrm{Cl})$ canopy environments as estimated from boreal toad physical models from mid-June to mid-September. Each curve is based on 10-day hourly averages centered on dates shown from 4 model arrays at SC. Other lines refer to air ( Air $)$ and water $\left(\mathrm{H}_{2} \mathrm{O}\right)$ temperatures (dashed lines, top panels) and relative humidity ( $R H$, thin solid line, bottom panels).

\section{DisCuSSION \& SignifiCANCE}

Our findings suggest although boreal toads risk reinfection by $B d$ when entering water sources at breeding sites in the Teton region (Figure 2), ample opportunities exist for them to reduce their level of infection by basking throughout the activity season (Figures 3-4).

With respect to 'independent persistence' of the pathogen $B d$, our findings argue that boreal toads are the primary source of $B d$ in the water of breeding sites, as zoospores were the most consistently detectable at this time (May, Fig. 2). However, even during breeding we were unable to detect $B d$ at 1 of 4 sites (SC). Postbreeding, the concentration of $B d$ zoospores in the water dropped to levels that were undetectable, or nearly so, by our method: $\sim 9$ of 10 samples after this time did not detect $B d$.

Our findings do not rule out the independent survival of $B d$ in water, yet they suggest that the pathogen does not proliferate in the absence of adult toads, and thus remains at low concentrations. We did not detect zoospore concentrations in water comparable to those typically used to induce deadly infection in boreal toads $\left(\geq 10^{4} /\right.$ liter). However, Carey et al. (2006) induced lethal chytridiomycosis in Colorado boreal toads at doses of $\sim 10$ zoospores per liter when toads were held in continuous contact with water for 42 days.
The environmental envelope we described using boreal toad physical models (Fig. 3 ) suggests that toads have a substantial number of hours to raise their body temperature to thresholds which may protect them from lethal chytridiomycosis (Fig.4). Hence, although a lethal infection from exposure to low concentrations of $B d$ zoospores ( $<10 /$ liter) is possible, we suggest it is highly unlikely given the typical semi-aquatic behavior of boreal toads during the majority of the summer activity season. Toads using open basking sites face high evaporation rates (Fig 3, bottom panels) and hence must select sites near water to enable frequent rehydration. This is consistent with the behavior we have observed from telemetry conducted at SC and BR during summer 2008.

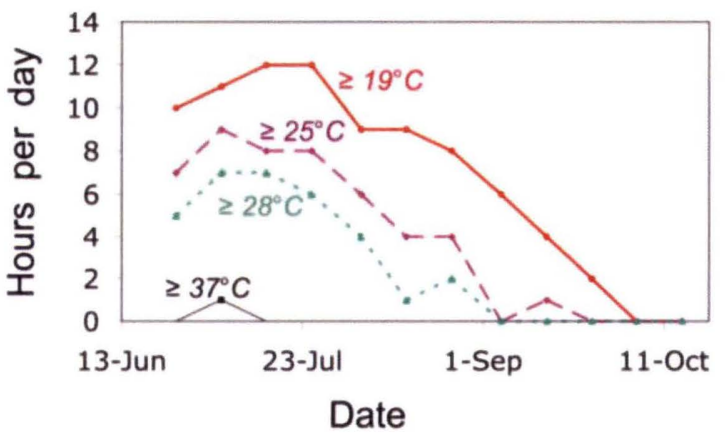

Figure 4. Average number of hours above four threshold temperatures for twelve 10-day sampling periods from midJune to mid-October. 
During summer 2008 one of us (PJM) conducted a telemetry study comparing two Wyoming populations of boreal toads (SC and BR) with two Colorado populations (Zirkel Mountains). By following individuals and their infection status over the course of 12 weeks, we hope to be able to ascertain how often boreal toad adults change $B d$ infection status and whether this change matches seasonal temperature patterns. Moreover, using both physical model arrays and repeated measurements of adult temperature in both regions, we hope to be able to ascertain whether the environmental conditions faced by boreal toads in Colorado differs substantially from that in Wyoming, pre-disposing them to greater likelihood of lethal chytridiomycosis. All of these efforts are enabling us to better understand the factors that determine the tipping point for outbreaks of lethal chytridiomycosis in amphibians, a subject of intensive research in amphibians worldwide (Rachowicz et al. 2005).

\section{LiTERATURE Cited}

Bartelt, P.E. and C.R. Peterson. 2005. Physically modeling operative temperatures and evaporation rates in amphibians. Journal of Thermal Biology 30:93-102.

Berger L, R. Speare, H.B. Hines, G. Marantelli, A.D. Hyatt, K.R. McDonald, L.F. Skerrat, V. Olsen, J.M. Clarke, G. Gillespie, M. Mahony, N. Sheppard, C. Williams and M. Tyler. 2004. Effect of season and temperature on mortality in amphibians due to chytridiomycosis. Australian Veterinary Journal 82(7): 31-36.

Boyle, D.G., D.B. Boyle, V. Olsen, J.A.T. Morgan and A.D. Hyatt. 2004. Rapid quantitative detection of chytridiomycosis (Batrachochytrium dendrobatidis) in amphibian samples using real-time Taqman PCR assay. Diseases of Aquatic Organisms 60:141-148.

Briggs, C.J., V.T. Vredenburg, R.A. Knapp and L.J. Rachowicz. 2005. Investigating the population-level effects of chytridiomycosis: an emerging infectious disease of amphibians. Ecology 86(12):3149-3159.

Carey, C., J.E. Bruzgul, L.J. Livo, M.L. Walling, K.A. Kuehl, B.F. Dixon, A.P. Pessier, R.A. Alford and K.B. Rogers. 2006. Experimental exposures of boreal toads (Bufo boreas) to a pathogenic chytrid fungus (Batrachochytrium dendrobatidis). EcoHealth 3:5-21.
Corn, P.S. 2007. Amphibians and disease: Implications for conservation in the Greater Yellowstone Ecosystem. Yellowstone Science 15(2):11-16.

Daszak P., A. Strieby, A.A. Cunningham, J.E. Longcore, C.C. Brown and D. Porter. 2004. Experimental evidence that the bullfrog (Rana catesbiana) is a potential carrier of chytridiomycosis, an emerging fungal disease of amphibians. Herpetological Journal 14 (4): 201-207.

Johnson, M.L. and R. Speare. 2003. Survival of Batrachochytrium dendrobatidis in water: quarantine and disease control implications. Emerging Infectious Diseases 9: 922-925.

Kriger K.M. and J.M. Hero. 2006. Survivorship in wild frogs infected with chytridiomycosis. EcoHealth 3(3):171-177.

Kirshstein J.D., C.W. Anderson, J.S. Wood, J.E. Longcore and M.A. Voytek. 2007. Quantitative PCR detection of Batrachochytrium dendrobatidis DNA from sediments and water. Diseases of Aquatic Organisms 77:11-15.

Lips K.R., R. Brem, R. Brenes, J.D. Reeve, R.A. Alford, J. Voyles, C. Carey, L. Livo, A.P. Pessier and J.P. Collins. 2006. Emerging infectious disease and the loss of biodiversity in a Neotropical amphibian community. Proceedings of the National Academy of Sciences USA 103(9):3165-3170.

Murphy, P.J., S. St-Hilaire, S. Bruer and P.S. Corn. 2008. Distribution and pathogenicity of Batrachochytrium dendrobatidis in boreal toads from the Grand Teton area of western Wyoming. EcoHealth (in press).

Muths, E., P.S. Corn, A.P. Pessier and D.E. Green. 2003. Evidence for disease-related amphibian decline in Colorado. Biological Conservation 110:357-365.

Piotrowski J.S., S.L. Annis and J.E. Longcore. 2004. Physiology of Batrachochytrium dendrobatidis, a chytrid pathogen of amphibians. Mycologia 96:9-15. 
Rachowicz, L.J., J.M. Hero, R.A. Alford, J. W. Taylor, J.A. T. Morgan, V.T. Vredenburg, J.P. Collins and C.J. Briggs. 2005. The novel and endemic pathogen hypotheses: Competing explanations for the origin of emerging infectious diseases of wildlife. Conservation Biology 19(5):14411448.
Spear, S,N., Maxon, S. Wolff and P.S. Corn .2005. Incidence and effects of chytrid fungus on boreal toads (Bufo b. boreas) in Grand Teton National Park. Moose, WY: USGS - NPS Final Report

Woodhams, D.C., R.A. Alford and G. Marantelli. 2003. Emerging disease of amphibians cured by elevated body temperature. Diseases of Aquatic Organisms 55:65-67. 